\title{
Performance of children and adolescents with PTSD on the Stroop colour-naming task
}

\author{
A. R. MORADI, ${ }^{1}$ M. R. TAGHAVI, H. T. NESHAT DOOST, W. YULE \\ AND T. DALGLEISH \\ From the Teacher Training University, Tehran, Isfahan University, Isfahan and Shiraz University, Shiraz, \\ Iran; and Department of Psychology, Institute of Psychiatry, London, and MRC Cognition and Brain \\ Sciences Unit, Cambridge
}

\begin{abstract}
Background. Investigators have used various experimental paradigms such as the Stroop colour naming test to study how adults with different emotional disorders process emotional information. However, to date, little research has been carried out on younger subjects.
\end{abstract}

Method. In the current experiment, children and adolescents with post-traumatic stress disorder (PTSD) and control subjects aged 9-17 years, participated in a modified Stroop colour naming task.

Results. The results indicated that the children and adolescents with PTSD showed increased Stroop interference for trauma-related material relative to neutral words and to the performance of the controls.

Conclusions. These findings indicate that attentional bias to trauma-congruent information is a function of PTSD in young age groups. The results are discussed with respect to the literature on information processing in PTSD.

\section{INTRODUCTION}

Attention biases for emotion-congruent information are recognized as a central feature of many cognitive theories of psychopathology (Beck, 1979; Bower, 1981; Power \& Dalgleish, 1997; Williams et al. 1997). The argument is that the presence of an emotional disorder serves to bias basic cognitive processing in favour of stimuli congruent to the individual's dominant emotions. Such biases lead to increased processing of emotional information, which exacerbates the disorder and consequently augments the level of bias and so on in a vicious circle (Power \& Dalgleish, 1997). A number of experimental paradigms have been used to investigate attentional processing of this kind (see Williams et al. 1997). Recently, the modified Stroop task has been the most frequent method of investigating such biases.

1 Address for correspondence: Dr Ali R. Moradi, Department of Psychology, Teacher Training University, 49 Mofath Avenue, Tehran, Iran.
The original Stroop colour-naming task consisted of colour names printed in different colour inks (e.g. the word 'red' was printed in blue ink) and the task was to name the ink colour while ignoring the content of the words. In his original experiment, Stroop (1935) found that, despite instructions to ignore the content, subjects' response latencies to naming the ink colours were longer when the words were themselves different colour names, relative to latencies to name the colours of neutral stimuli (coloured patches). This interference effect, as demonstrated by the longer latencies, was interpreted as the result of prolonged processing of the semantic content of the colour names.

The original Stroop task has since been modified to include emotion-related material such as threatening words (e.g. Mathews \& MacLeod, 1985). Subjects are required to name the colours in which either emotion-related or non-emotional words are printed. The results of several research studies have shown that patients are often slower to name the colour of a word 
that is associated with concerns relevant to their clinical condition (see Williams et al. 1996, for a review).

One area of fruitful application of this method has been to examine attentional processing of trauma-related information in post-traumatic stress disorder (PTSD). For example, Foa et al. (1991) investigated Stroop performance in survivors of rape with PTSD, survivors without PTSD and controls. Survivors with PTSD exhibited selective Stroop interference for words related to the trauma but this effect was not found in the other two groups. Similar profiles of results have been found in other studies where only the symptomatic group exhibited Stroop effects (e.g. Cassiday et al. 1992; Thrasher et al. 1994).

Despite a large body of research examining the modified Stroop effect in adults with emotional disorders, there has been far less interest in such processing biases in younger subjects. Taghavi (1996) in an unpublished study examined Stroop effects in children and adolescents with over-anxious disorder and found selective Stroop interference for threat-related words in the anxious group, relative to healthy controls. Similar results were reported by Martin et al. (1992) with spider phobic children. Finally, Schneider et al. (1992) in another unpublished study examined Stroop effects in children of adults with a diagnosis of panic disorder or phobic disorder. The results revealed that both groups exhibited selective Stroop interference relative to controls but only for words relevant to their parents' concerns. Similar findings were reported by Moradi et al. (1998) with young offspring of trauma survivors. Again, the children of the PTSD parents showed selective interference on threat-related words relative to the controls.

It is important to understand the nature of such processing biases in younger populations if we are to make theoretical claims concerning continuity across development in the processes underlying disorders such as PTSD (Yule, 1992); that is, if we are to understand whether the aetiological factors in PTSD are the same in child, adolescent and adult populations. For this reason, in the current study we extend the work investigating information processing biases for negative information to a group of children and adolescents with a diagnosis of PTSD. The hypothesis is that there will be increased Stroop interference for trauma-related material relative both to performance with non-trauma-related material and to the performance of a control group of children and adolescents with no psychiatric or psychological problems. Developmental aspects of bias will be examined using correlational analyses between age and an index of Stroop interference.

\section{METHOD}

\section{Subjects}

Twenty-three children and adolescents (11 boys and 12 girls), aged 9 to 17, who met Diagnostic and Statistical Manual of Mental Disorders (4th Edition, DSM-IV; American Psychiatric Association, 1994) and International Classification of Diseases (World Health Organization, ICD10 ; 1992) criteria for a primary diagnosis of PTSD, were matched on age, sex, verbal IQ and reading ability with a group of 23 children and adolescents (10 boys and 13 girls), aged 9 to 17 years, who had no psychiatric problems. All of the participants with PTSD were involved in either road traffic or personal violence events and were introduced by the clinicians of the Psychology Department of the Institute of Psychiatry, London. Diagnostic status was determined in a clinical assessment by mental health teams, including psychiatrists and psychologists before the participants were introduced to the experimenter. Consensual diagnosis by all members of the team was a requirement for selection. Most of the control group were recruited from secondary schools and a few of them from primary schools from different parts of London. Control subjects had no known history of emotional disorder or trauma according to parents and teachers. Colour-blind subjects and those who had low scores on Basic Reading (below 85) and British Picture Vocabulary (below 85) tests were excluded.

\section{Materials \\ Instrumentation}

An IBM (Thinkpad 755C TF1) portable computer with a 10 inch active-matrix TFT colour LCD screen was used to present the stimuli. A voice key was used to register the vocal response of the subjects automatically and to record the 
reaction time (RT). The sensitivity of the voice key could be increased or decreased by means of a control. The voice key connected to an adjustable head microphone (Bandridge EH620, Dynamic Headsets) worn by the subject.

\section{Word stimuli}

Sixty words were used as verbal stimuli. These consisted of 12 words from each of five word categories: happy (e.g. pleased, kindness, smile, excited, brilliant), categorized neutral (e.g. sheep, donkey, gorilla, parrot, duck), depressionrelated (e.g. helpless, lonely, friendless, crying, miserable), general threat-related (e.g. terrified, dark, ghost, petrified, horrible) and traumarelated (e.g. injured, emergency, hospital, blood, bandage). Each word was presented twice, such repetition being a standard technique with this methodology (Williams et al. 1996). The words were selected from a source of words produced by 231 primary and secondary school pupils (Neshat-Doost et al. 1999). All of the five categories were matched for length and frequency according to this source. Each word was presented once in each of two colours chosen at random from the four colours: green, yellow, red and blue.

\section{Procedure}

The test was carried out individually. Each subject was asked to sit in front of the computer, 18 inches from the screen, in a quiet room, without any disruptions. Before the main task, there were 18 practice trials, which were the same as the experimental trials except that the stimulus words were all uncategorized neutral words. In the main task, 120 stimulus words were presented in a new fully random order for each subject. The presentation time for each word was $1.7 \mathrm{~s}$. The inter-trial interval was $2.0 \mathrm{~s}$. The subject was asked to ignore the word and say out loud the colour into the microphone as quickly as possible. After 40 trials subjects were given a short rest. The task took about 15-20 min in total. Following the Stroop task the subjects were asked to participate in vocabulary (British Picture Vocabulary Scale (BPVS) short form; Dunn et al. 1982) and reading (Wechsler Objective Reading Dimensions (WORD), Basic Reading; Rust et al. 1993) tests, and finally they were asked to fill in depression (Depression SelfRating Scale (DSRS); Birleson, 1981) and anxiety (Revised Children's Manifest Anxiety Scale (RCMAS); Reynolds \& Richmond, 1978) measures. The PTSD group also completed the Revised Impact of Event Scale (IES; Horowitz et al. 1979).

\section{RESULTS}

One-way ANOVAs showed that there were no significant differences between the groups for age, verbal IQ, and reading ability, but that the PTSD group scored significantly higher on self-reported depression, $F(1,44)=11 \cdot 62, P<$ 0.001 , and anxiety, $F(1,44)=6.98, P<0.02$ (see Table 1). The PTSD group's mean score on the IES was comparable with that of a sample of child survivors of a shipping disaster (Yule, 1992). The groups were balanced for sex ratio, $x^{2}<1$.

Errors on the Stroop task were negligible and a one-way repeated measures ANOVA revealed no differences across Group or Word Type, or any interaction. The following analyses are for correct responses only. Outliers above $2000 \mathrm{~ms}$ and below $100 \mathrm{~ms}$ were removed, consistent with the previous literature. The overall pattern of results was unaffected by the removal of outliers.

The mean response latencies for the five word types are shown in Table 2. These data were submitted to a two-way, Group $(2) \times$ Word

Table 1. Means and standard deviations (S.D.) of psychological measures for children and adolescents with PTSD and control subjects (medians of age in square parentheses)

\begin{tabular}{|c|c|c|c|c|}
\hline & \multicolumn{2}{|c|}{ PTSD } & \multicolumn{2}{|c|}{ Controls } \\
\hline & Mean & (S.D.) & Mean & (S.D.) \\
\hline $\operatorname{Sex}(M: F)$ & $11: 12$ & & $10: 13$ & \\
\hline Age (months) & $\begin{array}{c}154 \cdot 83 \\
{[168 \cdot 00]}\end{array}$ & $(35 \cdot 06)$ & $\begin{array}{c}162 \cdot 83 \\
{[159 \cdot 00]}\end{array}$ & $(22 \cdot 72)$ \\
\hline Word $^{\mathrm{a}}$ & 101.52 & $(12 \cdot 01)$ & 98.43 & $(15 \cdot 64)$ \\
\hline BPVS $^{a}$ & 98.43 & $(15 \cdot 34)$ & $93 \cdot 59$ & $(17 \cdot 27)$ \\
\hline $\operatorname{DSRS}^{\mathrm{ab}}$ & $13 \cdot 52$ & $(7 \cdot 35)$ & $8 \cdot 48$ & $(4 \cdot 53)$ \\
\hline IES $^{\mathrm{a}}$ & $33 \cdot 55$ & $(19 \cdot 46)$ & - & - \\
\hline $\mathrm{RCMAS}^{\mathrm{ac}}$ & $14 \cdot 57$ & $(8 \cdot 25)$ & $9 \cdot 78$ & $(5 \cdot 12)$ \\
\hline
\end{tabular}

a RCMAS, Revised Children's Manifest Anxiety Scale; DSRS, Depression Self-Rating Scale: BPVS, British Picture Vocabulary Scale; WORD (Basic Reading), Wechsler Objective Reading Dimensions; IES, Revised Impact of Event Scale.

${ }^{\mathrm{b}}$ Significantly different across groups, $P<0.001$.

Significantly different across groups, $P<0.01$. 
Table 2. Means and standard deviations (S.D.) of colour naming response latencies (s) for neutral (animal), happy, threat, depressed and traumarelated words across the two groups, i.e. children and adolescents with PTSD and controls

\begin{tabular}{lcccccc}
\hline \hline & \multicolumn{5}{c}{ Word Type } \\
\cline { 3 - 7 } & & Neutral & Happy & Threat & Trauma & Depressed \\
\hline \multirow{2}{*}{ PTSD } & Mean & 0.94 & 0.95 & 0.94 & 0.99 & 0.97 \\
& (s.D.) & $(0 \cdot 17)$ & $(0 \cdot 16)$ & $(0 \cdot 15)$ & $(0 \cdot 17)$ & $(0 \cdot 17)$ \\
Control & Mean & $0 \cdot 77$ & $0 \cdot 77$ & $0 \cdot 79$ & $0 \cdot 76$ & $0 \cdot 76$ \\
& (s.D.) & $(0 \cdot 13)$ & $(0 \cdot 15)$ & $(0 \cdot 14)$ & $(0 \cdot 11)$ & $(0 \cdot 11)$ \\
\hline \hline
\end{tabular}

Type (5) mixed model ANOVA. The results showed a main effect of Group, $F(1,44)=17 \cdot 15$, $P<0.001$, with the PTSD group being slower overall. There was also a significant Word Type $\times$ Group interaction, $F(4,176)=4 \cdot 40, P$ $<0 \cdot 01$, but no effect of Word Type, $F(4,176)=$ $1 \cdot 04$, NS.

To examine this interaction, two ANOVAs examining Stroop performance of children and adolescents with PTSD and control groups separately for the five types of words were performed. Results revealed a significant effect of Word Type for the PTSD group, $F(4,88)=$ $3.24, P<0.05$, but not for the control group, $F(4,88)=1 \cdot 75$, NS.

To investigate the Word Type effect in children and adolescents with PTSD, a series of post-hoc comparisons was performed which compared the mean reaction times on the colour-naming task for each set of emotional words (i.e. happy, depressed, threat and trauma words) with neutral words using the Studentized Q statistic set at $P<0 \cdot 05$. There was a significant difference only between trauma words and neutral words.

To examine the relationships between subject age, DSRS, RCMAS and interference times, a series of correlations was performed across all subjects. Similar analyses were carried out for IES scores in the trauma group alone. There was a significant correlation between age and colournaming speed of neutral words, $r(45)=-0 \cdot 43$, $P<0.01$, with subjects being faster as they got older. Therefore, in order to control for general colour-naming speed, indices were calculated in which the mean reaction time (RT) to colourname neutral words was subtracted, in turn, from the mean RT to colour-name generally threatening, happy, and depression-related words. Because of the number of correlations, a protected alpha of $P<0.01$ was employed. There were no significant correlations.

\section{DISCUSSION}

The present study investigated biases in the processing of emotional information in children and adolescents with PTSD using the Stroop colour-naming task. The results indicated that subjects with PTSD were slower overall on colour-naming performance and selectively slower to colour-name trauma-related words relative to non-emotional material and compared to the performance of matched control subjects. Correlational analyses indicated that this was not an age-related effect and was maintained across the age-range studied of 9 to 17 years.

These findings are in line with those in the adult literature examining processing biases in PTSD with the same task (e.g. Foa et al. 1991; Thrasher et al. 1994). The overall slowing effect has been interpreted as a general effect of anxiety on cognitive processing. The differential slowing for trauma-related material has traditionally been interpreted (Williams et al. 1996) as providing evidence for a bias in attentional processing in favour of trauma-related information in trauma survivors, analogous to the symptom of hypervigilance in DSM (APA, 1994).

The fact that similar results have been obtained with a younger population adds further support to the argument (e.g. Yule, 1992) that there is continuity between the presentation of PTSD in adults and its manifestation in younger individuals. In order to progress meaningfully with this argument, it is essential to examine issues of continuity in underlying processes as well as in symptom presentation and studies of the present kind are a step in that direction.

In these terms, the present data suggest that attentional bias to threat may be a basic information processing function in traumatized individuals down to as young as 9 years and these data provide support for the extension of theories of adult information processing of emotional information (e.g. Williams et al. 1997) to younger populations. However, it must be noted that by 9 years of age the majority of 
milestones in cognitive development have been passed and there is a need for further research with younger children.

We would like to thank Dr Derek Bolton and his colleagues at the Psychology Department of the Institute of Psychiatry for allowing us to see the patients under their care. Also, we would like to thank Mr L. N. Law for help with computer programming.

\section{REFERENCES}

American Psychiatric Association (1994). Diagnostic and Statistical Manual of Mental Disorders, 4th edn. APA: Washington, DC.

Beck, A. T. (1979). Cognitive Therapy of Depression. Guilford Press: New York.

Birleson, P. (1981). The validity of depressive disorder in childhood and the development of a self-rating scale: a research report. Journal of Child Psychology and Psychiatry 22, 73-88.

Bower, G. H. (1981). Mood and memory. American Psychologist 36, 129-148.

Cassiday, K. I., McNally, R. J. \& Zeitlin, S. B. (1992). Cognitive processing of trauma cues in rape victims with post-traumatic stress disorder. Cognitive Therapy and Research 16, 282-295.

Dunn, L. M., Whetton, C. \& Pintilie, D. (1982). The British Picture Vocabulary Scale: Manual for the Short and Long Forms. Cromwell Press: London.

Foa, E. B., Feske, U., Murdock, T. B., Kozak, M. J. \& McCarthy,

P. R. (1991). Processing of threat-related information in rape victims. Journal of Abnormal Psychology 100, 156-163.

Horowitz, M. J., Wilner, N. \& Alvarez, Z. W. (1979). Impact of Event Scale: a measure of subjective stress. Psychosomatic Medicine 41, 209-218.

Martin, M., Horder, P. \& Jones, G. V. (1992). Integral bias in naming of phobia-related words. Cognition and Emotion 6, 479-486.

Mathews, A. \& MacLeod, C. (1985). Selective processing of threat cues in anxiety states. Behaviour Research and Therapy 23, 563-569.
Moradi, A., Neshat-Doost, H. T., Taghavi, M. R., Yule, W. \& Dalgleish, T. (1998). Performance of children of adults with PTSD on the Stroop colour-naming task. Manuscript submitted for publication.

Motta, R. W., Suozzi, J. M. \& Joseph, J. M. (1994). Assessment of secondary traumatization with an emotional Stroop task. Perceptual and Motor Skills 78, 1274.

Neshat Doost, H. T., Moradi, A. R., Taghavi, M. R., Yule, W. \& Dalgleish, T. (1999). The development of a corpus of emotional words produced by children and adolescents. Personality and Individual Differences (in the press).

Power, M. J. \& Dalgleish, T. (1997). Cognition and Emotion: From Order to Disorder. Psychology Press: Hove.

Reynolds, C. R. \& Richmond, B. D. (1978). What I think and feel: a revised measure of children's manifest anxiety. Journal of Abnormal Child Psychology 6, 271-280.

Rust, J., Golombok, S. \& Trickey, G. (1993). Wechsler Objective Reading Dimensions. Psychological Corporation/Harcourt Brace Jovanovich, Publishers: London.

Schneider, S., Unnewher, S., Florin, I. \& Margraf, J. (1992). Cognitive characteristics of children of panic patients. Paper presented at the International Congress of Psychology, Brussels (September).

Stroop, J. R. (1935). Studies of interference in serial verbal reactions. Journal of Experimental Psychology 18, 643-662.

Taghavi, S. M. R. (1996). Cognitive Aspects of Clinical Anxiety in Children and Adolescents. Ph.D. thesis, University of London.

Thrasher, S. M., Dalgleish, T. \& Yule, W. (1994). Information processing in PTSD. Behavioural Research and Therapy 32, 247-254.

Williams, J. M. G., Mathews, A. \& MacLeod, C. (1996). The emotional Stroop task and psychopathology. Psychological Bulletin 120, 3-24.

Williams, J. M. G., Watts, P. N., MacLeod, C. \& Mathews, A. (1997). Cognitive Psychology and Emotional Disorders, 2nd edn. Wiley: New York.

World Health Organization (1992). The ICD-10 Classification of Mental and Behavioral Disorders: Clinical Descriptions and Diagnostic Guidelines. WHO: Geneva.

Yule, W. (1992). Posttraumatic stress disorder in child survivors of shipping disasters: the sinking of the Jupiter. Psychotherapy and Psychosomatics 57, 200-205. 